\title{
PRINCIPLES OF DESIGNING WELL SEPARATORS
}

\author{
A.B. Feodorov* V.I. Afanasov V.N. Gaevsky S.P. Dunaeva R.S. Miroshnikov P.M. Kondrashov \\ Siberian Federal University, Krasnoyarsk, Russia
}

Vortex motion is effectively used in the development of wellbore filter designs. Further development of the principles of such design requires the development of some principles based on experimental observations and computer modeling. A constructive analogy between the wellbore filter and the Ranque vortex tube is shown. The results of experimental and theoretical studies of the vortex tube are applied as a basis for designing a well separator. Recommendations are formulated regarding the radius of the inner branch pipe of the downhole filter placed in the body. Approaches are discussed when choosing the length of the working section of the well separator, as well as the choice of the shape of the input cochlear, the size of the outlet diaphragm, and the shape of the sand suspension window.

Key words: Vortex Tube, Separation, Designing, Well Separator, Wellbore Filter

\section{LITERATURE REVIEW}

The Vortex currents make it possible to intensify the processes of mass transfer, organize cleaning and separation of the components of the working fluid. In recent years, understanding of many processes occurring in gas or liquid flows in a vortex tube has been achieved. This is due to the desire for a theoretical explanation of all the experimentally observed facts of such currents.

There are complications in the death of the axial motion [01-07]. Despite the significant ups and downs in the modeling and understanding of the effect], practical applications follow their course $[01,13]$. In our previous work, we discussed the features of the application of a particular construction [14-17] constructed with the aim of using the separation capabilities of the Ranque-Hilsh effect. Further discussion of our design led to an understanding of the independence of research on the physics of processes and the practice of constructing serial production. Our focus was mainly on the equipment of the oil and gas industry.

The desire to modernize the sectoral equipment leads to a gradual complication of structures. Additional elements are introduced that give a local win within the product. At the same time, designers forget about the possibilities of using physical effects. This is due to the specifics of the design school. There is also a reason for the inability of physics to consistently describe the essence of nonlinear effects.

The development of studies of the Ranke effect, leading to visual models, is limited to the standard case of a hollow, long (50 caliber) tube. There is the desire to introduce additional structural elements in the body of the tube. However, there is a danger of losing physical effect. Roll into a situation of minimalism. Create a construction "based" on the use of local centrifugal forces.

Regardless of the existing difficulties of physical theories, the practice of using vortex technologies does not stand still. In this regard, it is important to formulate the basic relationships and proportions of aggregates using the Ranque-Hilsh effect. The goal is to create various designs with internal elements introduced. Save useful physical effects and their combinations in the process of creating a serial aggregate.

Thread swirl is widely used in technical devices to organize and intensify various processes. As shown by experimental studies, intensive swirling of the flow has a great influence on the characteristics of the flow field. This, above all, is associated with the intensification of mass exchange.

The development and introduction into production of new technology requires the study of local, integral and turbulent properties of a swirling flow in various conditions.

It must be admitted that at present there is no unified opinion on the mechanism of energy separation and temperature stratification in such currents.

The most attention is drawn to the hypothesis of vortex interaction [01,14]. The calculations were made in [17]. They confirmed the formation in the separation chamber of two vortices rotating in one direction. These vortices move in opposite axial directions. This circumstance was first discovered experimentally in the experiments of Shults-Grunow [18].

In our experiments, the goal was to verify the observed effects for the conditions of particular designs. Sketch designing was carried out with the purpose of adaptation of requirements of model to the form of a serial well filter.

Regardless of the particular construction, interest is represented by a set of relationships. Criteria for the choice of design, dimensions ensuring the pumping of technologically required fluid volumes. The placement and dimensions of the internal elements (the red arrow in Figure 2) are investigated on the basis of physical technical models and outline design of the vortex tube options. The internal branch pipe in Figure 2 has the ratios of a conventional serial well filter. The radius of the nozzle is less than the radius of the central vortex. 
Such dimensions contribute to the partitioning of the central vortex formed due to the Ranke effect.

A lot of work is devoted to the study of the characteristics of the vortex tube [01-18]. Experimental studies of dynamic vortices are associated with significant difficulties. The reason is the complexity of observing the phase velocities of the liquid jets. Significant progress is achieved through computer modeling. Comparison of spatial images of currents with experimental data allows us to judge the processes occurring in the vortex.

Computer simulation allows you to vary the geometric parameters of the vortex tube and establish the necessary relationships between the structural elements. Numerical calculations provide information on the physics of the processes that are taking place.

Here, the existing technical solutions are compared and the recommendations derived from the existing studies of the vortex tubes are formulated.

\section{RESULTS AND DISCUSSION}

The simplicity of the vortex tube design and high reliability are attributed to its main advantages as devices for producing cooled gas masses [01]. In this paper, the discussion is limited to mass transfer processes. The construction of the counter flow vortex tube Ranque-Hilschis is quite simple (Figures 1 and 2). The main structural elements of the vortex tube are: a body with a swirling nozzle inlet 1, a diaphragm at the end of the input and a reversal element in the opposite end.

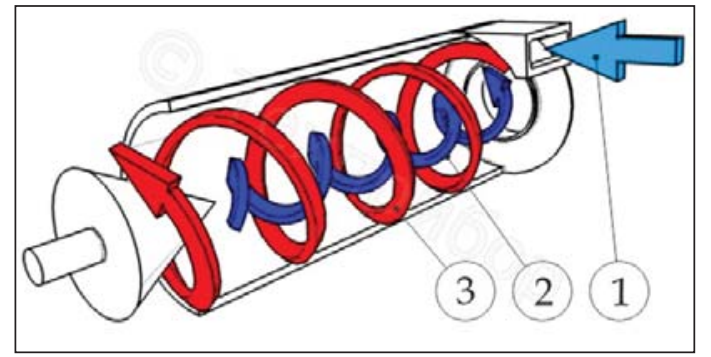

Figure 1: Scheme of counterflow vortex separator 1 - input stream, 2 - axial flow, 3 - near-wall flow

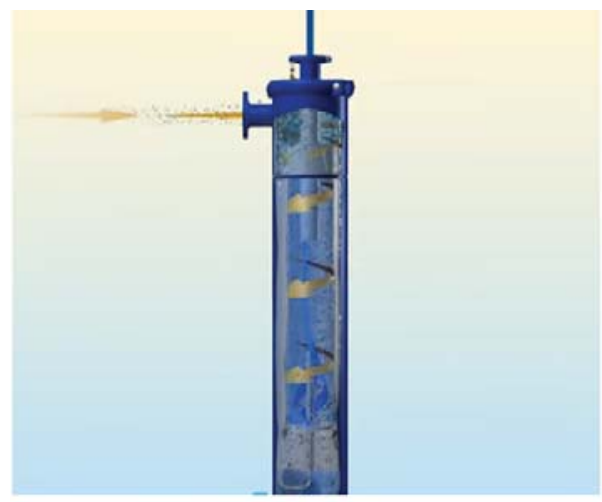

Figure 2: LAKOS EJPX Centrifugal Separator for industrial applications [19]
The figures show that the fluid flows in both devices look similar.

The process of separation of vortices, known as the vortex effect or Rank's effect, is realized during the flow of an intensely twisted flow. Flows are formed along a cylindrical channel. On the end surfaces of the channel, restrictive elements are installed - a choke on the "hot" and a diaphragm with a central hole at the "cold" ends of the pipe.

The physics of the phenomenon of redistribution of vortices in a pipe is the result of complex gas-dynamic processes. The peripheral vortex moves from the nozzle inlet to the throttle, and the axial vortex in the opposite direction. Their energy and gas dynamic interaction forms the basis of the physical model for describing the separation process, known as the vortex interaction hypothesis.

The optimal designs are wellbore filter type of the Ranque vortex tube. It is necessary to reject various kinds of return elements of the throttling end of the tube. A design with a length of at least 50 gauges is preferred. The choice is made in favor of the maximum length of interaction between the central and peripheral vortices. The area of mass transfer increases. Providing the maximum volume of unperturbed rotation of the central vortex promotes maximization of the sand removal zone. The absence of superfluous internal elements at the lower end of the tube is positive for minimizing the thickness of the transition layer between the central and peripheral vortex.

All these limitations are directed toward eliminating micro vortices in the interaction zone of the two main vortices. A long zone is created to clean up the ascending vortex flow.

As a result of experimental studies, the proportions between the axial and parietal vortex were determined [01]. The radius of the axial vortex is from 0.6 to 0.8 parts from the radius of the vortex tube. The preservation of the effectiveness of mass transfer processes requires the preservation of the unperturbed structure of the axial vortex. The additional cylinder in the axial area must be chosen with a radius of at least 0.6 the radius of the vortex tube. Otherwise, the destruction of the axial vortex will reduce the efficiency of separation of the fluid streams. And as a consequence, create conditions for the penetration of sand into the axial vortex.

Effective separation of vortices occurs with a tube length of more than 20 gauges. It is desirable to have 50 calibers. Vortex tube designs use specific recurrent elements or a cone-shaped body profile. That allows you to reduce the length of the tube to 5 - 7 calibers. In the absence of restrictions on the length of the downhole filter, it should be selected in the range of 20 to 50 calibers, preferably, closer to 50 . In this case, the quality of the axial symmetry of the axial vortex is improved from the returning throttle to the outlet nozzle. From this follows the conclusion: the length of the outlet branch pipe should be a small part of the length of the tube. It should 
be noted that increasing the length of the vortex chamber contributes to an additional filtration effect. In this case, the influence of the counterflow effect increases.

The nozzle input is profiled along the Archimedes' spiral with a minimum radius equal to the radius of the vortex chamber. The input window reaches 0.4 of the tube radius and has a square cross-section.

The output diaphragm at the end of the nozzle inlet is $40 \%$ of the sectional area of the tube body.

The lower outlet for the entrainment of the sandy suspension should be designed as a ring. The central part of the return end is designed in the form of a cone. Such geometry ensures a sufficiently effective separation of the vortices. The peripheral vortex bearing the sandy suspension is separated from the axial vortex of the purified liquid.

\section{CONCLUSION}

A comparative analysis of the Ranke vortex tube and a borehole filter is carried out. The experience of twophase fluids in the conditions of vortex flows has been used [19-29]. It is shown that their constructions are fundamentally similar. Increasing the efficiency of the well separator is achieved, as a rule, by introducing additional structural elements. Each such element is the source of the twists associated with it. The dialectics of the process consists in the delicate balance of the vortex and laminar flows. In principle, the rotational vortex motion in the downhole filter may contain laminar sections. It is known from the studies [01-19] of vortex tube physics that the axial vortex rotates like a solid body. Introducing additional elements into the body of the vortex tube, it is necessary to take into account their effect on the phase picture of the liquid flows.

The diameter of the central branch pipe introduced into the design of the well separator should be $60 \%$ of the diameter of the housing. This constructive solution is dictated by the requirements of minimization of disturbances on the emerging structure of the ascending vortex. A good choice separates the action of the elementary centrifugal force or the formation of the structure of fluid flows according to the Ranke effect type. In practical terms, this is a different efficiency of sand removal from the central vortex. The optimal design allows us to avoid micro vortices and reverse pulling of sand into the central vortex.

On the pattern of liquid motions in the vortex tube, guidelines for designing effective borehole filters are formulated without attracting unnecessary elements. Numerical calculations and computer visualization can be used to refine the fluid flow characteristics in a well separator, as is done in the study of the characteristics of vortex tubes.

\section{ACKNOWLEDGEMENTS}

The research was supported by the Federal Target Program "Research and development on the priority directions of development of the scientific technological complex of Russia for 2014-2020". Action 1.3 "Carrying out the applied research directed towards the creation of advanced scientific- technological potential for the development of branches of economy" (unique identifier of applied researches (project) RFMEFI57817X0236).

\section{REFERENCES}

1. Sh.A.Piralishvili, V.M.Polyaev, M.N.Sergeev, The vortex tube. Research, theory, concepts (Moscow: Energomash UNPC, 2000).

2. C.U.Lindestrom-Lang, An experimental study of the tangentional velocity profile on Ranque-Hilsh vortex tube, Riso Report, n 116. pp. 2-43, 1965.

3. J.C.Crittenden, R.R.Trussell, D.W. Hand, K.J. Howe, G. Tchobanoglous MWH's Water Treatment: Principles and Design: Third Edition (2012) available at: https://onlinelibrary.wiley.com/doi/ book/10.1002/9781118131473.

4. G.Z.Broun, A.Roshko On density effect and large structure in turbulent mixing lauers, I. Fluid Mech, vol. 64, pp. 778-816, 1974.

5. M. Kurosaka, Acoustik streminq in swirlinq flow and Ranque - Hilsh (Vortex tube) effect, I. Fluid Sci., vol.124, pp. 139-172, 1993.

6. K.Stephan, Investigation in a Vortex tube /K.Stephan [e.a.], Ibid, vol. 26, n. 3, pp. 341-348, 1983.

7. P.K.Singh, An experimental performance evaluation of vortex tube. I.E.(i) J.-MC.-January, vol.84, pp.149153, 2004.

8. W.R.Michałek, J.G.M.Kuerten, J.C.H.Zeegers, R.Liew LES of the ranque-hilsch vortex tube, ERCOFTAC Series 20, pp. 679-686, 2015.

9. K.V.Lebedinskii, N.E.Kurnosov, A.A.Nikolotov, D.P.Alekseev lonization of air in a ranque-hilsch vortex tube and the method of obtaining uni- and bipolar ionization, Journal of Engineering Physics and Thermophysics, vol. 88(6), pp. 1476-1482, 2015.

10. Y.Xue, M.Arjomandi, R.Kelso Experimental study of the flow structure in a counter flow Ranque-Hilsch vortex tube, International Journal of Heat and Mass Transfer, vol. 55 (21-22), pp. 5853-5860, 2012.

11. V.Alekhin, V.Bianco, A.Khait, A.Noskov Numerical investigation of a double-circuit Ranque-Hilsch vortex tube, International Journal of Thermal Sciences, vol. 89, pp. 272-282, 2015.

12. S.E.Rafiee, M.B.M.Sadeghiazad Three-dimensional computational prediction of vortex separation phenomenon inside the Ranque-Hilsch vortex tube, Aviation, vol. 20(1), pp. 21-31, 2016. 
13. Y.Xue, M.Arjomandi, R.Kelso Experimental study of the thermal separation in a vortex tube, Experimental Thermal and Fluid Science, n. 46, pp. 175-182, 2013.

14. A.B.Feodorov, V.I.Afanasov, R.S.Miroshnikov, V.V. Bogachev Concept of modernization of input device of oil and gas separator, IPDME 2017 IOP Publishing IOP Conf. Serios: Eafth and Environmental Science, vol. 87, n. 082020, 2017.

15. V.I.Afanasov, V.V.Abramov, R.S.Miroshnikov, V.N. Gaevsky, S.P.Dunaeva Vortex tube in well separators // IOP Conference Series: Materials Science and Engineering, vol. 327(2), n. 022071, 2017.

16. V.V.Abramov, V.I.Afanasov, A.S.Lunev, A.M.Shakhmin, A.M.Fayziev, Patent RF 156936. Well Sand Separator. 2015

17. O.V.Kazantseva, Sh.A.Piralishvili, A.A.Fuzeeva Numerical simulation of swirling flows in vortex tubes, High Temperature, vol. 43(4), pp. 608-613, 2005.

18. M.Bovand, M.S.Valipour, S.Eiamsa-Ard, A. Tamayol Numerical analysis for curved vortex tube optimization, International Communications in Heat and Mass Transfer, vol. 50, pp. 98-107, 2014.

19. W.Frohlingsdorf, H.Under, Numerical investigation of the compressible flow and the energy separation in the Ranque - Hilsch vortex tube, Int. J. Heat and Mass Transfer, n 42, pp. 415-422, 1999.

20. F.Shults-Grunow, Die Wirkungweise des Ranque wirbelrohres, Kaltetechnik, n. 2, pp. 273-284, 1950.

21. A.P.Merkulov, The vortex tube and its usage in technic. (Moscow: Mashnostroenie, pp. 8-16, 1969).
22. A.F.Gutsol, The Rank effect, Successes in Physical Sciences, vol. 167, n.6, pp. 665-687, 1997.

23. M.G.Ranque, Experiences sur la detente giratoire avec production simulanees d'un echappementd'airchaud et d'airfroid, Journal de Physique et le Radium (in French), Supplement, vol. 7, n. 4, pp. 112-114, 1933.

24. M.Sibulkin, Unsteady, Viscous, Circular Flow. Part 3: Application to the Ranque-Hilsch Vortex Tube, Journal of Fluid Mechanics, n. 12, pp.269-293, 1962.

25. K.Stephan, S.Lin, M.Durst, F.Huang, and D.Seher, A Similarity Relation for Energy Separation in a Vortex Tube, Int. J. Heat Mass Transfer, vol. 27, n. 6, 911-920, 1984.

26. Presentation of the LAKOS downhole filter: available at: https://www.youtube.com/watch?v=GWMFgiWSfEO

27. M.S.Iliessu, G.D.Ciosan, F.A.Avellan Analysis of the cavitating draft tube vortex in a Francis turbine using particle velocimetry measurements in two-phase flow, J. of Fluids Engineering, vol. 130, p.10, 2008.

28. R.I.Edling, B.I.Barfaield, C.I.Haan Vortex velocity production with emphasis directed toward vortex tube sediment trapdesign, Pap ASAE for Anny. Meet, n.11, Pap. 75- 2548, p. 25, 1975.

29. U.Vabistas Georgios, Tangentional velocity and static pressure distributions in vortex chambers, AIAA, vol. 25(1), n.8, pp. 174-286, 1987

Paper submitted: 05.03.2018.

Paper accepted: 30.05.2018.

This is an open access article distributed under the CC BY-NC-ND 4.0 terms and conditions. 